\title{
Core text
}

\section{S. A. Morse}

Early Precambrian Basic Magmatism. Edited by R. P. Hall and D. J. Hughes. Blackie: 1990. Pp.486. £85, \$141.

TERRA est omnis divisa in partes tres: core, mantle and crust. The core is metal and mostly liquid, in which fluid flow generates our magnetic field. The mantle, about 63 per cent of the Earth's mass, is dominantly magnesium-iron (mafic, basic) silicate rock, and the crust ( 5 per cent) is mostly silicon-aluminium (felsic, acid) silicate rock. Plastic upwelling in the mantle conveys heat from the depths of the Earth, and ultimately drives the tectonic motion of the rigid plates. The decompression of hot mantle rock in these upwellings causes melting to occur at some places and times, and the melt is mafic magma that either erupts onto the solid surface of the Earth or, if it does not erupt, cools to form intrusive igneous bodies. By crystallization of mafic magma, partial melting of solid rock and other processes, crust has been generated indirectly or directly from the mantle over geological time. Subject to geophysical contraints, all our real knowledge of the internal constitution of the Earth comes from the samples of the mantle represented by mafic magmatism (including blocks of solid mantle ripped off and carried up) and, indirectly, from the nature of the crust. For this reason, mafic magmatism throughout geological time, and especially in early Precambrian time (3.8-2 gigayears ago),

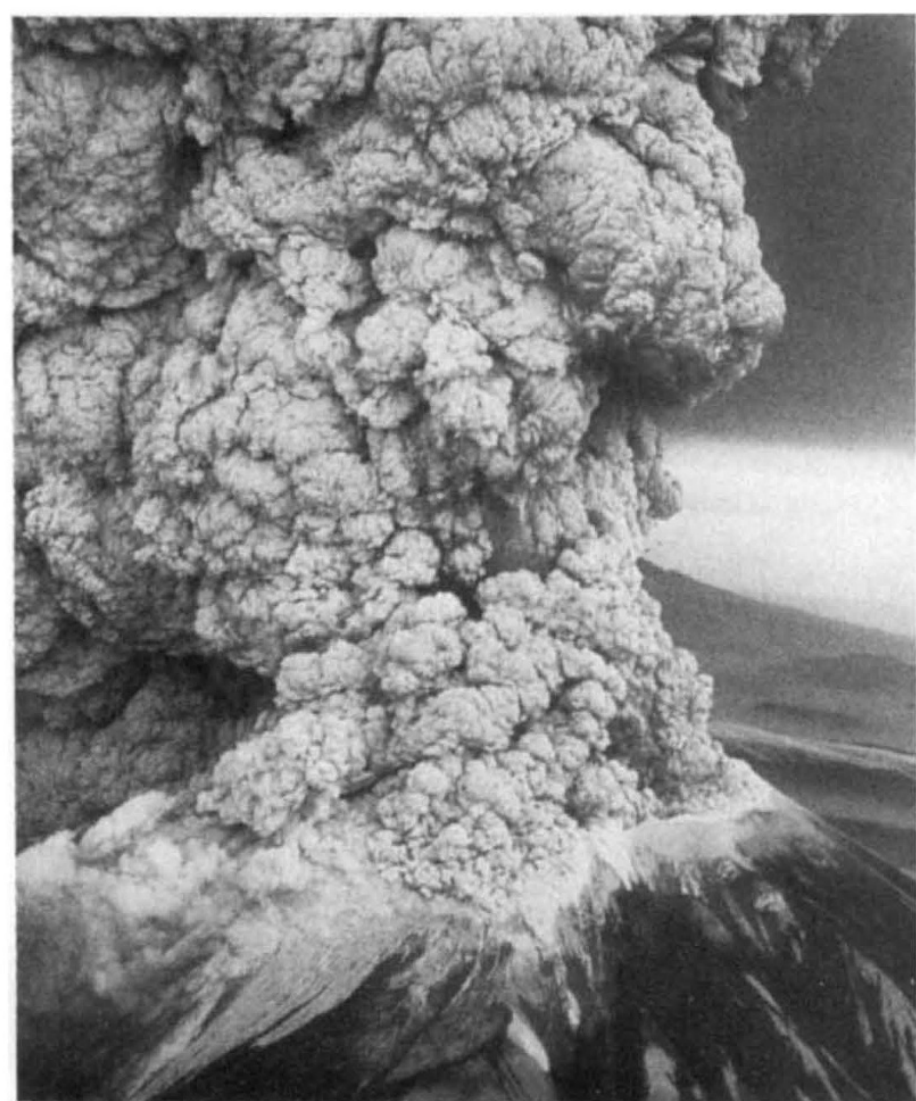

Smoky atmosphere - after the initial horizontal eruption of Mount St Helens in 1980, a vertical explosion forced a column of hot gas, ash and rock $19 \mathrm{~km}$ into the atmosphere. Our Mysterious Planet: Mysteries of the Natural World, edited by Philip Whitfield, offers possible answers to questions concerning volcanoes, earthquakes, lightning, global climate, gravity, the demise of the dinosaurs and other of the Earth's enigmas. Published by Cassell, price is $£ 18.95$. forms the rock upon which our church of knowledge is built. That is the reason for such a book as this.

The notion of acid and basic in rocks and silicate melts has nothing to do with hydrogen ions, but stems instead from the old concept of silica $\left(\mathrm{SiO}_{2}\right)$ as silicic acid. Rocks poor in silica (and conversely, rich in magnesium-iron silicate) are, by default, basic. The trend away from this tradition among researchers in the United States, and towards the use of the acronyms felsic and mafic, evidently still awaits wide acceptance in Europe. An encouraging aspect of this entire collec- tion of articles in Early Pecambrian Basic Magmatism is the abundant demonstration that original rock chemistry can be recognized in the oldest rocks through screen of variable (but quantifiable) alteration and metamorphic recrystallizaStudents of modern volcanism who doubt this fact should take another look

The first part of the book deals with general aspects of early Precambrian magmatism, including that on the Moon. One wonders why the editors stopped there, when Mars and some meteorites could certainly qualify in this context. This part
United States and too little on those in Canada.

A main aim of studies such as those described here is the prospect of learning about the thermal history of the Earth, for the particular mineralogical and chemical characters of basic magmatism directly reflect the potential temperature of the upwelling source rocks. But there are serious impediments to making general statements about the bulk Earth through time, most of them reviewed carefully here by Bickle. There are unresolved paradoxes in the conflicting evidence from different parts of the crust. One such paradox is ignored. At present, between 20 and 40 per cent (many favour the upper limit) of the heat coming from within the Earth is released by the freezing of the core. Most of the emphasis on the thermal history of the Earth dwells on the secure knowledge that internal heat production from radioactive decay has decreased by about threefold since 3.5 gigayears ago. From this fact alone it can be concluded that the Earth now cools at a slower rate than in the past, and was hotter earlier. But core freezing could conceivably accelerate as radiogenic heat production decreases, in effect leading to a more-or-less constant release of heat over time. The record of the rocks evidently permits this model, but perhaps does not allow a clear choice among the alternatives. It is surprising not to find core heat brought centrally into the discussions in this volume.

What emerges, however, is a great wealth of information conveniently collected, but an equally great confusion about what it all means. The concluding remarks by the authors of most chapters serve as clear

concludes with a chapter on mineralization associated with early Precambrian mafic magmatism, most notably the major (and classically strategic) deposits of nickel, chrome, gold and platinum group elements. The second part consists of regional syntheses, inevitably covering some of the same ground as in part $I$, but in some cases containing different points of view. There are strongly argued accounts of signally important occurrences in South Africa and Australia, and welcome chapters on little-known terranes in China and South America. Some may perceive too much detail on sites in the pointers to further study, but also, with distressing frequency, as statements of conflicting interpretations still unresolved even after decades of enlightened research in the field and laboratory. It is, perhaps, not surprising that this should be the case where the geological record is complex and incomplete but, in sum, it does suggest that the science is not yet up to the challenge of the rocks. Good news for the young.

S. A. Morse is in the Department of Geology and Geography, University of Massachusetts, Amherst, Massachusetts 01003, USA. 